\title{
ERIKSON Philippe (éd.), Trophées. Études ethnologiques, indigénistes et amazonistes offertes à Patrick Menget
}

\section{Diego Madi Dias}

\section{OpenEdition}

Journals

Édition électronique

URL : https://journals.openedition.org/jsa/15262

DOI : 10.4000/jsa.15262

ISSN : 1957-7842

Éditeur

Société des américanistes

Édition imprimée

Date de publication : 15 décembre 2017

ISSN : 0037-9174

\section{Référence électronique}

Diego Madi Dias, « ERIKson Philippe (éd.), Trophées. Études ethnologiques, indigénistes et amazonistes offertes à Patrick Menget », Journal de la Société des américanistes [En ligne], 103-2 | 2017, mis en ligne le 15 décembre 2017, consulté le 29 septembre 2022. URL : http://journals.openedition.org/jsa/15262 ; DOI : https://doi.org/10.4000/jsa.15262

Ce document a été généré automatiquement le 29 septembre 2022.

Tous droits réservés 


\title{
ERIKSON Philippe (éd.), Trophées. Études ethnologiques, indigénistes et amazonistes offertes à Patrick Menget
}

\author{
Diego Madi Dias
}

\section{RÉFÉRENCE}

ERIKSON Philippe (éd.), Trophées. Études ethnologiques, indigénistes et amazonistes offertes à Patrick Menget, Nanterre, Société d'ethnologie (Recherches américaines, 10), 2016, 2 vol. (294 p.-[16] p. de pl., 262 p.-[16] p. de pl.), bibliogr., fotos em cores e em preto e branco, tabl.

1 Devemos saudar a publicação de Trophées..., edição cuidadosa de Philippe Erikson em homenagem a Patrick Menget, cujos textos reunidos permitem retraçar as principais linhas de desenvolvimento e institucionalização da antropologia amazonista na França. Editados em dois volumes, os estudos oferecidos a Menget são corolários de uma profícua colaboração entre pesquisadores diversos que trabalharam no Brasil e passaram pela Universidade de Nanterre na segunda metade do século $\mathrm{xx}$, contribuindo para a notória "virada amazônica" na etnologia francesa ${ }^{1}$. Conforme explica Erikson (p. 15), a figura de Patrick Menget assume nesse contexto um papel crucial em função de sua trajetória como "aluno de Lévi-Strauss mas que se formou nos Estados Unidos e regressou à França depois de um longo desvio pelo Brasil". Philippe Erikson descreve a Universidade de Nanterre nos anos 1970 e 1980 como uma espécie de caldeirão do americanismo tropical, e Menget surge nesse cenário como um grande articulador e entusiasta das trocas intelectuais ${ }^{2}$. Com efeito, os trabalhos de Menget apresentam abordagens precursoras, tratando de problemas e ideias que vieram depois a integrar o vocabulário básico da antropologia amazonista. Por exemplo, sua tese de doutoramento, intitulada Au nom des autres e defendida em 1977, constitui um dos primeiros esforços de descrição etnográfica da vida social e simbólica de uma 
população ameríndia a partir da centralidade das relações que se estabelecem com o exterior. A associação particular com um estrangeiro ou inimigo aparece na etnografia de Menget sobre os Ikpeng como uma relação positiva, confirmando a intuição de LéviStrauss (1942) sobre o estatuto da guerra e dos ritos antropofágicos entre os Tupinambá e antecipando elaborações conceituais importantes como as noções de alteridade constitutiva (Erikson 1986, 1996), predação ontológica (Viveiros de Castro 1992, 1996a, 1996b) e predação familiarizante (Fausto 1999a, 1999b, 2001).

2 As trinta e uma contribuições presentes neste Festschrift estão organizadas em cinco grandes temas que ressoam com o trabalho de Patrick Menget. Cada artigo pode ser lido como um troféu de guerra trazido do campo e oferecido a Menget - em reconhecimento à sua obra, que inspirou uma geração inteira de etnólogos, mas sobretudo para celebrar o triunfo de suas ideias na produção de uma agenda internacional de investigação americanista.

3 O percurso acadêmico de Menget é o tema da primeira seção, que agrupa testemunhos de Eduardo Viveiros de Castro, Anthony Seeger, Marcos Guevara Berger e Renato Athias, além de um ensaio pujante de Márnio Teixeira Pinto. Os textos abordam diferentes momentos da vida acadêmica do antropólogo homenageado, permitindo reconstituir uma trajetória profissional que se confunde com a própria história da disciplina. Viveiros de Castro contextualiza a obra de Patrick Menget em relação ao conjunto de problemas suscitado pelo amazonismo franco-brasileiro nas décadas de 1980 e 1990; nesse sentido, ressalta a "função constitutiva do inimigo e da guerra para a reprodução das formas sociais ikpeng". Em um texto de agradecimento, Seeger relembra a defesa de seu trabalho de conclusão de curso em Harvard na primavera de 1967, uma das primeiras bancas de avaliação em que participava Patrick Menget. Guevara Berger e Athias evocam o clima intelectual em Nanterre, respectivamente nos anos 1970 e 1980: o primeiro recupera o método estrutural de análise comparada da mitologia ameríndia por meio dos exemplos bribri (Costa Rica) e guna (Panamá); o segundo sublinha a importância da interlocução com Menget para sua análise da composição de sistemas interétnicos como relativa à mobilidade ou residência nômade. Finalmente, a contribuição de Teixeira Pinto se concentra nos anos 1990 e 2000, oferecendo uma síntese dos desdobramentos teóricos da etnologia realizada na Amazônia nesse período; por meio de uma arqueologia do conceito de alteridade no debate americanista, o autor argumenta que essa noção aparece na etnografia ikpeng realizada por Menget ao mesmo tempo como descoberta etnográfica e formulação teórica.

4 A segunda seção de Trophées... tematiza a prática do trabalho de campo e suas implicações éticas, ressaltando o envolvimento do etnógrafo - seu engajamento com o contexto sócio-político - como parte essencial do projeto antropológico que atravessa a obra de Menget. A seção tem início com um texto do próprio Menget, que analisa seu trabalho entre a universidade e a militância em favor da causa indígena nos últimos quarenta anos. Com base em diferentes experiências de campo, cinco de seus ex-alunos, todos formados em Nanterre, dão continuidade ao dossiê. Bruce Albert descreve o caminho que o levou de uma antropologia engajada à produção compartilhada de conhecimento, refletindo sobre a etnografia como gênero de escrita que conjuga a autoridade e a responsabilidade constitutivas do pacto etnográfico: "escrever em nome dos outros". Os textos seguintes apresentam relatos intimistas e anedotas de campo de Jean-Michel Beaudet, Florent Kohler, Véronique Boyer e Hélène Erikson Weisbrod. 
Esses autores discutem problemas capitais para a reflexão antropológica pós-colonial: ética e dialogismo; sistemas de valor e modelos indígenas de racionalidade; etnografia como experiência forjada entre a tentativa e o erro; equivocação estética: a dimensão artefatual da pessoa amazônica, valor e materialidade, tradição e criatividade cultural.

5 A terceira seção reúne contribuições sobre o problema etnológico da couvade, tema clássico trabalhado por Menget no cruzamento entre a etnografia amazônica, a antropologia do parentesco e a história das ideias. À luz da teoria proposta por Menget, Philippe Erikson apresenta uma etnografia do parto e cuidados neonatais entre os Matis. Retomando a questão da couvade como técnica de gestão dos laços de substância na Amazônia Ocidental, o autor confere atenção particular à primeira ornamentação de um bebê como ritual de saída do resguardo para os pais. Ao mesmo tempo, a ornamentação corporal permitiria vislumbrar o prolongamento e uma transformação do tratamento simbólico dispensado pelos Matis à consubstancialidade. Emmanuel de Vienne, em uma inflexão perspectivista, descreve a couvade trumaï como estado de indiferenciação substancial em que o comportamento dos pais acaba por "chover" no bebê (xuxla), isto é, assume um efeito difuso sobre ele. Nesse contexto, os Trumaï ressaltam o perigo de animalização potencial ou contaminação ontológica, sublinhando a importância de se manterem em um campo olfativo reservado aos humanos. RoseFrance de Farias Panet analisa a construção do corpo entre os Canela através da circulação de fluidos corporais. Em diálogo com os escritos de Menget, a autora traz uma nova amplitude para a dimensão de gênero que perpassa o desenvolvimento infantil e a constituição da pessoa timbira no Brasil Central. Émilie Stoll parte da couvade e seu contraponto - o incesto - como estratégia analítica para revelar o arsenal de práticas, ideologias e sistemas de pensamento no contexto de uma população amazônica ribeirinha no Baixo Tapajós (Brasil). Anne-Marie Peatrik, assumindo uma perspectiva comparativa, enriquece o dossiê couvade com um exemplo proveniente da África Oriental. Com base em sua etnografia entre os Meru (Quênia), a autora reflete sobre a ausência de uma discussão sobre a couvade na literatura africanista, mostrando a pertinência dessa noção para explicar fenômenos relativos ao ciclo de vida no continente. Laurent Barry empreende uma genealogia do conceito de paternidade, propondo uma reflexão brilhante sobre a síndrome da couvade no Ocidente como demonstração ritual da paternidade. $O$ autor analisa a emergência histórica do modelo genético (ou "paternidade biológica"), destacando uma superposição entre ser e tornarse pai, isto é, entre a razão biológica e a lógica social. Frederico Delgado Rosa finaliza o dossiê couvade com um ensaio sobre as origens da noção de animismo em Edward Tylor - teórico clássico da couvade -, contribuindo para recolocar uma articulação cara a Menget, entre o debate amazonista e a história da Antropologia.

6 Em torno da guerra e dos ritos funerários, a quarta seção tem início com a publicação de um texto inédito de Patrick Menget - escrito em 1978 e que permite, mais uma vez, retraçar as bases da discussão amazonista que se estabeleceu nas últimas décadas. Aliança e violência são apresentadas como dimensões interdependentes da socialidade no complexo interétnico xinguano, interpretação que se tornou o esquema conceitual básico para análise das relações com entidades não humanas na Amazônia. Dominique Buchillet analisa as causas da perda demográfica entre os indígenas brasileiros, mostrando que as teorias nativas da doença e da morte desempenham um papel importante tanto para a morbimortalidade quanto para a possibilidade de retomada populacional. Marc Lenaerts, por meio de exemplos diversos (principalmente Arawak e Tupi), investiga o sentido da morte como fenômeno conceitual mas também concreto, 
expresso na Amazônia por uma "economia simbólica" (ou escatologia) mas também por uma linguagem comum (elementos de uma tanatologia ameríndia?). Anne-Marie Losonczy assina um belo artigo em que discute os conceitos em torno da morte na região afro-colombiana do Chocó, apresentando uma reflexão existencial nativa que está ancorada nas noções de sombra e sonho e na experiência da embriaguez. Vincent Hirtzel traz uma contribuição importante em que ressalta a coafinidade como arranjo relacional sui generis, prevista na terminologia de parentesco e que se manifesta no combate ritual yurakaré. Com base em uma etnografia dos duelos de flechas realizados até recentemente no piemonte andino, o autor demonstra a existência de um antagonismo institucionalizado que não pode ser descrito pelo modelo de "afinidade potencial" proposto por Viveiros de Castro. Oiara Bonilla apresenta a etno-história paumari por meio de suas representações míticas e cosmológicas que permitem vincular diferentes figuras da alteridade ao paradigma da violência, da guerra e da predação. Magda Helena Dziubinska explora as dinâmicas de perpetuação da hostilidade entre os Shipibo e os Kakataibo da Amazônia peruana; com especial originalidade, a autora parte de um vocabulário comum entre o futebol e a guerra para demonstrar em seguida que as competições esportivas podem ser pensadas como uma nova maneira de rivalidade e reprodução social da assimetria na Amazônia. Mickaël Brohan apresenta duas narrativas míticas recolhidas entre os Cavineños, povo de língua takana e que habita a Amazônia boliviana. Tratando da escatologia takana, bem como da origem da feitiçaria e da guerra, essas narrativas encerram a quarta seção de Trophées... com demonstrações vivazes da sofisticação intelectual ameríndia em torno da morte, da violência e do xamanismo.

7 A quinta e última seção de Trophées... é dedicada à noção de cultura e suas aspas contemporâneas (Carneiro da Cunha 2009). Patrick Menget realiza uma reflexão sobre a popularidade das concepções antropológicas de pluralismo e relativismo cultural, ressaltando a importância de uma postura intelectual relativista para o estudo das éticas e moralidades. Carlos Fausto apresenta o conceito kuikuro de ügühütu traduzido por "cultura", "tradição", "costume"-, analisando sua operatividade primeira no mundo xinguano mas, sobretudo, na relação com os brancos e suas tecnologias. Na mesma direção, Terence Turner trata das lutas políticas kayapó estabelecidas nas últimas décadas por meio da apropriação das tecnologias de informação e comunicação. $O$ artigo registra a emergência de uma nova força política, jovem e feminina, entre os Mẽbêngôkre Mentuktire; encerra com um relato em primeira pessoa de Mayalú Waurá Txukarramãe - filha de Megaron e neta classificatória de Ropni -, que fundou em 2012 o movimento Mẽbêngôkre Nyre (jovens Mẽbêngôkre). Jean-Pierre Goulard estuda as estratégias de linguagem que estiveram na base do projeto jesuíta de transpolarização, isto é, transposição genérica de uma polaridade religiosa por meio da perenização de dois personagens da cosmologia tupi (Toupan e Geropari). O autor analisa em seguida a acomodação de uma noção cristã de deus entre os Tikuna no alto Solimões a partir dos termos Tupana e Yurupari. Jérémy Deturche recorre às origens míticas do kampo entre os Katukina para ressituar sua utilização em perspectiva essencialmente ameríndia. Tendo conhecido um verdadeiro sucesso em contexto new age, o veneno de sapo (kampo) passou a ser utilizado por parcelas da população urbana no Brasil em função de suas propriedades eméticas e purgativas. A contribuição de Deturche é interessante na medida em que aponta para um "retorno às fontes" ou reindigenização do kampo, cuja utilização katukina está relacionada à caça, prestando-se à ativação de um potencial predador. Manuela 
Carneiro da Cunha oferece uma versão francesa de seu artigo clássico sobre "xamanismo e tradução", publicado no Brasil em 1998 e desde então leitura obrigatória nos cursos de etnologia americanista (que no Brasil chamamos "etnologia ameríndia"). Em linhas gerais, Carneiro da Cunha argumenta que o xamã amazônico seria um tradutor de perspectivas. Valentina Vapnarsky e Andrea-Luz Gutierrez-Choquevilca encerram Trophées... de maneira retumbante, oferecendo ao leitor uma degustação do requinte lírico ameríndio. Vapnarsky nos presenteia com três poemas de Briceida Cuevas Cob, representante da nova corrente de poesia maya, iik'il t'aan (palavras de vento). Gutierrez-Choquevilca, por sua vez, apresenta duas melopeias yuyachina, gênero de discurso performativo empregado no contexto das relações amorosas entre os Runa da Amazônia peruana. Trophées... então chega ao fim com imagens da noite e da escuridão, com encantações propagadas pela voz da anhuma e do tucano de bico vermelho.

8 Festschrift grandioso, Trophées... é fruto do esforço e da generosidade do editor em reunir, traduzir e disponibilizar em francês um conjunto formidável de pesquisas etnológicas, indigenistas e amazonistas. Mas Trophées... é também fruto do esforço de antropólogos de muitas partes em traduzir as teorias indígenas, filosofias outras, assumindo a perspectiva das pessoas com quem aprendemos e ressaltando assim a beleza que povoa seus mundos.

\section{BIBLIOGRAPHIE}

\section{CARNEIRO DA CUNHA Manuela}

1998 "Pontos de vista sobre a floresta amazônica: xamanismo e tradução", Mana, 4 (1), p. 7-22.

2009 Cultura com aspas e outros ensaios, Cosac \& Naify, São Paulo.

DESCOLA Philippe e Anne-Christine TAYLOR (orgs)

1993 L'Homme, 126-128 (dossier thématique “La remontée de l'Amazone : anthropologie et histoire des sociétés amazoniennes").

ERIKSON Philippe

1986 “Altérité, tatouage et anthropophagie chez les Pano : la belliqueuse quête du soi", Journal de la Société des américanistes, 72 (1), p. 185-210.

1996 La griffe des aïeux. Marquage du corps et démarquages ethniques chez les Matis d'Amazonie, Peeters (Langues et sociétés d'Amérique traditionelle, 5 ; SELAF, 358), Louvain/Paris.

FAUSTo Carlos

1999a "Of Enemies and Pets: Warfare and Shamanism in Amazonia", American Ethnologist, 26 (4), p. 933-956.

1999b “Da Inimizade: Forma e Simbolismo da Guerra Indígena”, Adauto Novaes (org.), A Outra Margem do Ocidente, Companhia das Letras, São Paulo, p. 251-282.

2001 Inimigos Fiéis: História, Guerra e Xamanismo na Amazônia, EDUSP, São Paulo. 
LÉVI-STRAUSS Claude

1976 [1942] "Guerra e comércio entre os índios da América do Sul”, Egon Schaden (org.), Leituras de etnologia brasileira, Cia. Editora Nacional, São Paulo, p. 325-339.

VIVEIROS DE CASTRO Eduardo

1992 From the Enemy's Point of View. Humanity and Divinity in an Amazonian Society, University of Chicago Press, Chicago.

1996a "Images of nature and society in Amazonian ethnology", Annual Review of Anthropology, 25, p. $179-200$.

1996b “Os pronomes cosmológicos e o perspectivismo ameríndio", Mana, 2 (2), p. 115-144.

\section{NOTES}

1. Vista Descola e Taylor (1993).

2. A partir do final dos anos 1980, Menget colaborou com a organização de um ciclo franco-britânico de encontros americanistas, além de atuar na criação do Séminaire d'anthropologie américaniste (SAA), espaço incontornável de discussão que se mantém por quase 30 anos graças ao vigor de Bonnie Chaumeil, recebendo até hoje muitos pesquisadores estrangeiros de passagem por Paris.

\section{AUTEURS}

DIEGO MADI DIAS

LAS, Collège de France 